\title{
VITAMIN C EXCRETION IN CHILDREN, WITH PARTICULAR REFERENCE TO RHEUMATIC FEVER
}

\author{
BY \\ J. D. KEITH, * M.D., and EVELYN M. HICKMANS, PH.D., M.Sc.
}

(From the Birmingham Children's Hospital)

In the study of vitamin $\mathrm{C}$ deficiencies a large volume of work has accumulated in the literature. A considerable amount of the work based on biochemical estimations is conflicting owing to sources of error in method and to other interfering factors. The interpretation of the results obtained and their application to clinical data thus becomes difficult in many instances. The purpose of this investigation was to study the excretion of vitamin $C$ in normal children and in children suffering from various diseases, with particular reference to rheumatic fever, and at the same time to investigate the limitations in interpreting results obtained by biochemical estimation of the vitamin in urine.

\section{Previous investigations}

Harris and Ray (1935) found the normal adult excreted 15-30 mgm. of ascorbic acid in the urine in twenty-four hours on a normal diet. Since then, other investigators have found similar figures, and Hawley and others (1936) give 15-28 mgm. as the normal daily excretion in an adult. In children, Hess and Benjamin (1934) reported that appreciable amounts of vitamin C could be detected in the urine only when large amounts were present in the diet. They concluded that the amounts of the vitamin in the urine of children under normal dietary conditions is negligible and when present in significant amounts represents an excess which appears after complete saturation of the tissues. Rohmer and others (1934) found measurable amounts in the urine of infants. When they were put on a diet low in vitamin $C$ they continued to excrete it in the urine. From this it was concluded that they could synthesize vitamin $C$ in the body. In older children, it was found that the output fell to unappreciable levels when a deficient diet was used.

Harris and Ray (1935), studying scorbutic infants, found low amounts in the urine, viz. 0.4-0.7 mgm. per day. After treatment, when they became

* Atholl-Moynihan Scholar, University of Birmingham. 
saturated, excretion varied from 1.4 to $2.4 \mathrm{mgm}$. (two cases). In control infants the daily excretion was $1-3 \mathrm{mgm}$. They suggest that children excrete the same amount of the vitamin as adults when expressed in terms of body weight.

Most of the experimental work relating to infection and vitamin $C$ has been on animals. Harde and Phillippe (1934) showed that the adrenal cortex of animals dying from diphtheria toxins had reduced vitamin $C$ content. Furthermore, when 2 M.L.D. of diphtheria toxin was in contact with $10-20 \mathrm{mgm}$. of ascorbic acid for one hour it lost some of its toxic properties. The classical symptoms of diphtheria were not produced in guinea-pigs inoculated with this amount of altered toxin, whereas controls could not withstand the effect of 2 M.L.D. They found the ascorbic acid content of the adrenals and livers of laboratory animals was reduced in many other infections and intoxications. Harde and Rothstein (1935) estimated the vitamin C excretion in ten cases of pneumonia and found the output was slightly less than normal. Saturation tests revealed a greater degree of unsaturation than normal.

From experimental work on animals, Rhinehart and Mettier (1934) presented evidence that rheumatic fever is due to a vitamin $\mathrm{C}$ deficiency associated with infection. Guinea-pigs rendered scorbutic and sub-scorbutic by vitamin Cdeficient diets were infected with a streptococcus. They developed lesions on the heart valves regarded as similar to those of acute rheumatic fever. A mosaic arrangement of cells at the junction of the heart valves was found on histological section, but no typical Aschoff bodies could be seen. Other workers have produced similar lesions in guinea-pigs, but no one has succeeded in producing typical Aschoff bodies as found in acute rheumatic fever.

Perry (1935) studied the excretion of vitamin $C$ in the urine following a single test dose of $500 \mathrm{mgm}$. He used five acute cases of rheumatic fever and six quiescent cases. Three in each group showed no apparent deficiency. The others were soon brought to a state of saturation by repeated doses. He concluded that vitamin $C$ deficiency was not an important factor in the production of acute rheumatic fever. Sendroy and Schultz (1936) in a recent investigation examined thirty-three patients from this point of view. Thirteen were suffering from acute rheumatic fever, thirteen were inactive convalescent cases of rheumatism and seven were controls. They were all given $250 \mathrm{mgm}$. of ascorbic acid daily for seven days and the vitamin $C$ excreted in the urine was estimated quantitatively over that period. Eight of the acute rheumatic cases showed some deficiency, but of these eight, two had previously had a poor diet and six had been vomiting, which, it was concluded, accounted for most of the deficiency. In any case the deficiency was slight when the output of the controls was considered. It was concluded there was no support for the concept that a condition of ascorbic acid deficiency is a predisposing factor in rheumatic fever. These authors also fed large doses of ascorbic acid over a period of several months to a group of cases of rheumatism. The clinical manifestations of the disease were not demonstrably affected.

A contrary view is taken by Abbasy, Hill and Harris (1936), who found a striking difference between the range of values for the excretion of vitamin $\mathrm{C}$ in the urine of rheumatic patients (active and convalescent) and those of control subjects. The average daily output was less in the rheumatism group than in the controls, but was almost identical with that of a group of children with active tuberculosis. They recommend the use of orange juice therapeutically and prophylactically in rheumatic fever, and suggest that the low value of vitamin C in the urine might be used in conjunction with clinical evidence as a diagnostic index of juvenile rheumatism for revealing the presence of a continued latent infective process. 


\section{Present investigation}

The vitamin $C$ in the urine was estimated quantitatively by the method of Harris (1935). Urines were examined immediately they were obtained during the day. The night urine was collected in a bottle containing 50 c.c. of acetic acid and examined as early as possible in the morning. In this way the minimum alterations in vitamin $C$ due to standing were obtained. Specimens were collected for three days and the average for twenty-four hours determined.

Diet.-The diet provided was the usual hospital diet and supplied a daily intake of approximately $\mathbf{4 0} \mathrm{mgm}$. of ascorbic acid for children between four and thirteen years with whom this study is mainly concerned. It would have been more satisfactory to place each child investigated on a diet free from vitamin C and to administer ascorbic acid in weighed quantities. However, since so many children suffering from a variety of diseases in various parts of the hospital were studied, this was decided to be impracticable. If this test was to prove useful in the routine study of cases the simplest possible régime seemed desirable. The vitamin $C$ in the diet was kept as constant as possible during the period of investigation. Using relatively large groups of patients it was considered possible to draw conclusions from the results obtained in this way after estimating the daily excretion of vitamin $C$.

Wide variation in the amount of vitamin $C$ excreted was found in children of the same age and on the same diet. As a rule, however, older children excreted more than the younger ones. The average excretion in twenty-four hours for a group of thirty-nine children who had little or no evidence of infection in the medical and surgical wards of the hospital was $9.7 \mathrm{mgm}$. Their ages were from two to thirteen years. When this group was divided in two according to ages, it was found the average for those between two and six years was $5.5 \mathrm{mgm}$. and $11.5 \mathrm{mgm}$. for those between seven and thirteen years. This indicates a definite increase in output with age, but when the variations in each group are considered the relationship appears less definite. Those in the first group (two to six years) varied in their excretion in twenty-four hours from $3.9 \mathrm{mgm}$. to $25.0 \mathrm{mgm}$. and in the second group (seven to thirteen years) from 4.5 to $35.6 \mathrm{mgm}$. The main point in these observations is that the total daily excretion of vitamin $C$ provides inadequate information to determine the presence or absence of a deficiency. A similar variation in results was noted when test doses were used.

A daily test dose of $500 \mathrm{mgm}$. of ascorbic acid has been used by several investigators to determine the degree of saturation of a patient. This amount was used in this study and administered daily while quantitative changes of the vitamin in the urine were measured. A diversity in response was found in different patients. Thus, in one patient the amount of the vitamin excreted rapidly rose to $200 \mathrm{mgm}$. per day and then continued at this level, while in another a much higher amount was reached. One child excreted $480 \mathrm{mgm}$. (96 per cent. of the test dose) before assuming a constant output at this level. Similar results were obtained by Hawley and co-workers, who found a marked 
variation in twelve adults in response to test doses. They suggest that factors, hitherto unknown in the urine, may interfere at times and in certain individuals with the accurate measurement of the vitamin.

It was found difficult to ascertain the point where saturation was reached. A normal child may excrete nearly $50 \mathrm{mgm}$. of vitamin $\mathrm{C}$ after one test dose of $500 \mathrm{mgm}$. About two-thirds of the normal cases in this series were found to excrete slightly more than this after the first test dose. After daily administration of $500 \mathrm{mgm}$. vitamin $C$ it required several days to reach a maximum excretion. It appeared most probable that this maximum occurred when an abnormal degree of saturation was reached. Because this maximum varied widely from one child to another, it was not considered a suitable basis for comparison, and for the purposes of this investigation a child has been considered saturated when after a test dose of $500 \mathrm{mgm}$. of ascorbic acid he excreted $50 \mathrm{mgm}$. in his urine in the following twenty-four hours.

The response to test doses is best studied in a vitamin C-deficient state such as scurvy. At this hospital during the past two years, nine children suffering from scurvy have been investigated in this way, and it is interesting to note that these infants required almost as much ascorbic acid to saturate them as an adult with the same disease. They required from $1.5 \mathrm{gm}$. to $3.25 \mathrm{gm}$. of ascorbic acid, whilst an adult with scurvy, reported by Archer and Graham (1936), required from 2 to $3 \mathrm{gm}$. to produce a similar state of saturation.

Infants with scurvy, in spite of severe manifestations of the disease, continue to excrete small amounts of the vitamin in the urine. Sometimes after therapeutic doses of vitamin $\mathrm{C}$ are given, the amount in the urine falls still further and remains low until a state of saturation is approached. Variations in the output of vitamin $C$ after administration of pure ascorbic acid to an infant suffering from scurvy and during the healing process are shown in the following case :

L.D., aged eight months, was admitted to hospital on September 9, 1936, with pain and swelling in the legs of one month's duration. He had been fed on cow's milk, water and sugar from birth, and had never received any orange juice. The skiagrams of arms and legs showed the typical changes of scurvy. He was not given orange juice at first, but ascorbic acid was administered in doses of $500 \mathrm{mgm}$. These doses are indicated in fig. 1, which also shows the output of ascorbic acid in the urine during the period of observation. Orange juice was started, one teaspoonful thrice daily, on October 3,1936, and increased to one oz. twice a day on October 8 . This was stopped subsequently whenever tests were done for vitamin $C$ in the urine. Skiagrams of the bones were taken on several occasions to indicate the progression of the reparative process. The consecutive evidences of clinical and pathological improvement may be set down as follows, and it is interesting to note that they do not coincide with one another in time. (1) The symptoms of pain and irritability disappeared completely within the first two days after the start of treatment. (2) Judging by the arbitrary standard described above, saturation occurred six days after admission, i.e. his excretion of vitamin $C$ showed a sudden rise to over $50 \mathrm{mgm}$. after five successive doses of $500 \mathrm{mgm}$. of ascorbic acid. However, when a few days were allowed to lapse with no treatment, the response to another test dose was again very low, and several doses had to be given to bring the excretion 
up once more to over $50 \mathrm{mgm}$. (3) It was not until November 10 that, following one dose of $500 \mathrm{mgm}$. of ascorbic acid, the output was immediately over $50 \mathrm{mgm}$., and several doses were not necessary to produce this amount. (4) Healing was not complete in the skiagrams until December 12, viz. fourteen weeks after the beginning of treatment.

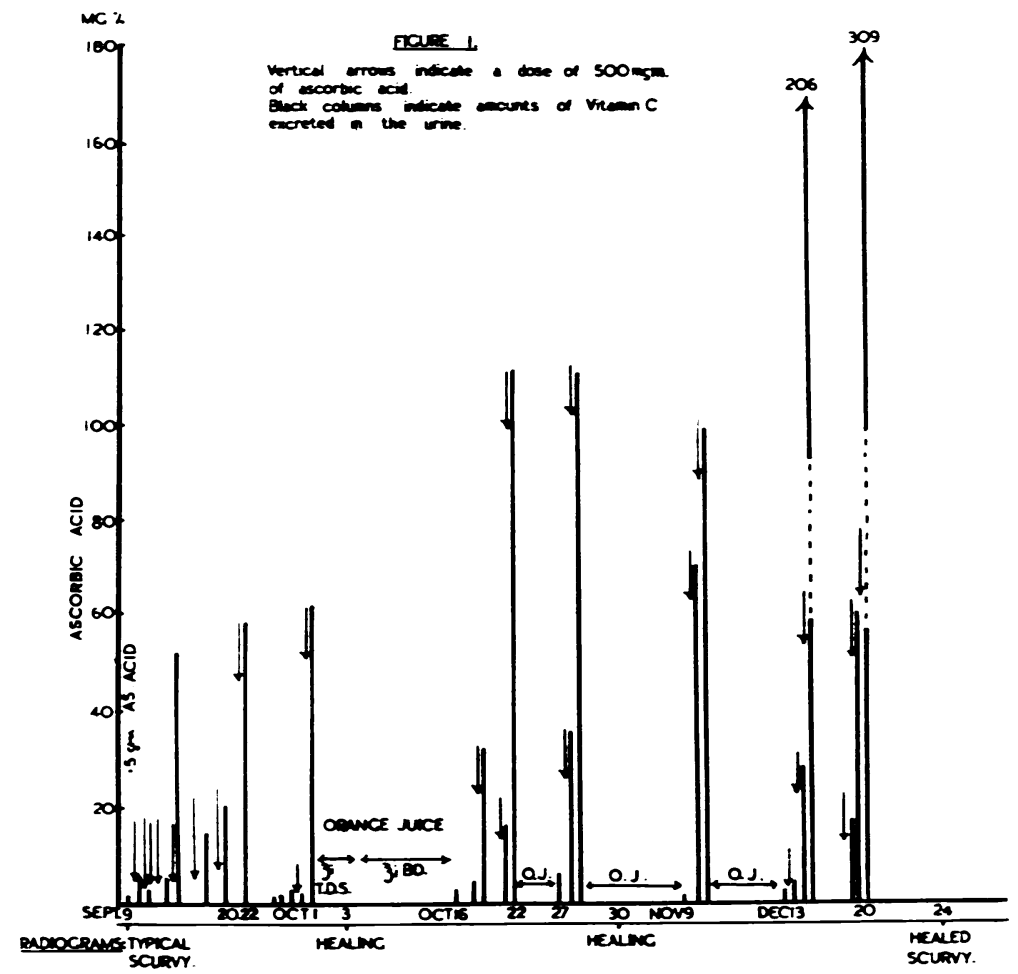

This serves to illustrate some of the difficulties in interpreting saturation tests in relation to scorbutic or sub-scorbutic patients. While it does not take many doses of ascorbic acid to produce a sudden and marked rise in the excretion of vitamin $C$ (five consecutive doses of $500 \mathrm{mgm}$.) in a child with acute scurvy, it is many weeks before the patient is completely cured. Biochemically it is not easy to differentiate between the various stages of the disease. For this reason recognition of sub-scurvy by this means has been regarded as indefinite and interpretation of results made with reserve. 


\section{Results}

Table 1 shows the output of ascorbic acid by children in a control group in this hospital. Sixty-nine children who had been admitted to the medical and surgical wards with little or no evidence of active infection were chosen for this group. They had been admitted for hernial repair, removal of naevi, epilepsy, mild or questionable bronchiectasis, and were investigated shortly after admission to hospital and while on the ordinary hospital diet. The average daily output of vitamin $C$ in the urine was found to be $9.7 \mathrm{mgm}$. Eighteen of these patients were then given daily test doses of $500 \mathrm{mgm}$. of ascorbic acid and the amount appearing in the urine was estimated : 61 per cent. excreted $50 \mathrm{mgm}$. or more following the first dose. The rest required two or three doses to produce this response in the urine, but none required more than three.

TABLE 1

\section{OUTPUT OF ASCORBIC ACID BY 39 MEDICAL AND SURGICAL PATIENTS WITH LITTLE OR NO EVIDENCE OF INFECTION}

Average daily excretion of ascorbic acid during control period $=9.7 \mathrm{mgm}$.

$$
\text { Range }=3.9-35.6 \mathrm{mgm} \text {. }
$$

Divided into Age Groups.

A. 2-6 years : average daily output $=5.5 \mathrm{mgm}$. ascorbic acid.

Range $=3.9-25 \mathrm{mgm}$.

B. 7-13 years : average daily output $=11.5 \mathrm{mgm}$. ascorbic acid. Range $=4 \cdot 5-35 \cdot 6 \mathrm{mgm}$.

18 children were then given daily test doses of $500 \mathrm{mgm}$. of ascorbic acid by mouth. 11 out of 18 required 1 dose before 24 hours' output reached $50 \mathrm{mgm}$. . 61 per cent. 2 out of 18 required 2 doses before 24 hours $^{*}$ output reached $50 \mathrm{mgm}$. . 11 per cent. 5 out of 18 required 3 doses before 24 hours $^{*}$ output reached $50 \mathrm{mgm}$. . . 28 per cent.

Table 2 shows the results obtained by tests carried out on eighteen patients at the convalescent home associated with the hospital. These children were recovering from empyema, asthma, chronic bronchitis, nephritis, and severe upper respiratory tract infection. The diet was similar to that given to the children referred to in table 1 . The average daily output was $9.3 \mathrm{mgm}$. Fifteen of these children were then given daily test doses of $500 \mathrm{mgm}$. of ascorbic acid. Seven, or 46 per cent. required one dose to produce a response of $50 \mathrm{mgm}$. or more in the urine in the twenty-four hours following. All were 'saturated ' by the third dose. Although the average daily output during the control period was the same as for those in table 1 , the response to test doses of vitamin C was less satisfactory, and it would appear that these children did not have the same stores of the vitamin and were therefore unsaturated in comparison. 
TABLE 2

\section{OUTPUT OF ASCORBIC ACID BY CONVALESCENT PATIENTS RECOVERING FROM VARIOUS DISEASES SUCH AS EMPYEMA, ASTHMA, BRONCHIECTASIS, GENERAL DEBILITY}

Average diet of the convalescent home.

Average daily output during control period of 18 cases was $9 \cdot 3 \mathrm{mgm}$.

15 were then given a daily dose of $500 \mathrm{mgm}$. ascorbic acid.

7 required 1 dose before 24 hours' output reached $50 \mathrm{mgm}$. $\quad . . \quad \ldots \quad \ldots 46$ per cent. 6 req aired 2 doses before 24 hours $^{\circ}$ output reached $50 \mathrm{mgm}$. . . . . . 40 per cent. 2 required 3 doses before 24 hours output reached 50 mgm. $\quad \ldots \quad \ldots \quad \ldots 14$ per cent.

Table 3 records the results on six patients who were suffering from severe infection such as acute pneumonia, advanced tuberculosis and advanced Hodgkin's disease. The average daily output was $8.4 \mathrm{mgm}$. and only one was saturated after the first dose of ascorbic acid.

TABLE 3

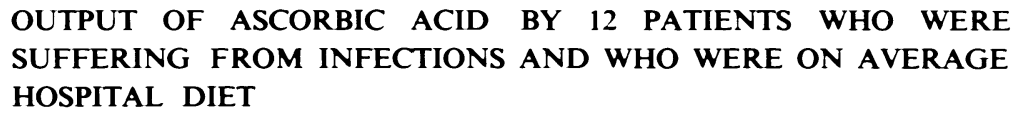

Average 24 hours' output of ascorbic acid in the urine $=8.4 \mathrm{mgm}$.

6 were then given $500 \mathrm{mgm}$. of ascorbic acid daily.

1 required 1 dose of ascorbic acid before 24 hours output reached $50 \mathrm{mgm}$.

2 required 2 doses of ascorbic acid before 24 hours $^{\circ}$ output reached $50 \mathrm{mgm}$.

3 required 3 doses of ascorbic acid before 24 hours $^{\circ}$ output reached $50 \mathrm{mgm}$.

Tables 4 and 5 deal with the rheumatic fever patients studied. In table 4 are recorded the results in acutely-ill cases at the time of admission to hospital. The vitamin $C$ in the diet was about the same as that of the children in the other groups. The average daily output was $21.5 \mathrm{mgm}$. This is almost double the figure for the controls; the factors influencing this will be discussed later : 50 per cent. were saturated after the first dose, and none required more than three doses to produce a response of $50 \mathrm{mgm}$. ascorbic acid in the urine. This indicates a mild degree of unsaturation of stores as compared with the controls.

TABLE 4

PATIENTS WITH ACUTE RHEUMATIC FEVER ON AVERAGE HOSPITAL DIET AS TOLERATED AT THE TIME OF ADMISSION

Average daily output during 24 hours' control for 18 cases $=21 \cdot 5 \mathrm{mgm}$.

These 18 cases were then given $500 \mathrm{mgm}$. ascorbic acid daily.

9 required 1 dose before 24 hours' output reached $50 \mathrm{mgm}$. $\quad \ldots \quad \ldots \quad \ldots \quad 50$ per cent.

7 required 2 doses before 24 hours' output reached $50 \mathrm{mgm}$. $\quad \ldots \quad \ldots . \quad \ldots 39$ per cent.

2 required 3 doses before 24 hours' output reached $50 \mathrm{mgm}$. . . . . . 11 per cent. 
Table 5 deals with fifty-one convalescent rheumatic patients. The average daily output was $12.4 \mathrm{mgm}$., whilst children convalescing from other diseases in the same institution averaged $9 \cdot 3 \mathrm{mgm}$. per day. Eighteen were given daily test doses and 61 per cent. of these were found to be 'saturated' after the first dose. One child required four consecutive doses to put his excretion up to $50 \mathrm{mgm}$. a day in spite of the fact that he had been receiving an adequate diet of vitamin $\mathrm{C}$ for several months. He was not ill and showed no other signs of deficiency of this vitamin. It seems likely that certain unknown interfering factors were present which produced this unusual result.

Since many of the acute cases of rheumatic fever were receiving salicylates and bicarbonate, it was decided to give similar doses of these drugs to a group of the controls and study the effect on the excretion of vitamin C. Fifteen of the children in the control series (table 1) were used for this purpose. The average daily output of those chosen was found to be $12 \cdot 2 \mathrm{mgm}$. Then 50 grains of sodium salicylate and 100 grains of sodium bicarbonate were administered each day for three days. During this treatment the average daily excretion of ascorbic acid rose to $15.9 \mathrm{mgm}$. These results are recorded in table 6 , and may explain in part the higher average excretion of ascorbic acid in the acute stages of the disease, since about one half of those included in table 4 were receiving similar doses of sodium salicylate and sodium bicarbonate. The figures in table 4 have been analysed with this in mind and some increased excretion was noted in the group receiving salicylates. Of the eighteen patients with acute rheumatic fever seven were receiving sodium salicylate and bicarbonate and had an average daily excretion of $24 \mathrm{mgm}$. ascorbic acid; while the eleven who were receiving no medication had an average daily excretion of $20 \mathrm{mgm}$. ascorbic acid. Some of those not receiving salicylates excreted abnormally large amounts of vitamin $\mathrm{C}$ daily. On the other hand these findings may possibly be explained on the basis of some recent work by Payne (1936), who showed that there is an increase in the total acidity and various acid constituents of the urine in acute rheumatic fever. Hawley, Daggs and Stephens (1937) have shown that an increase in the acidity of the urine increased the excretion of ascorbic acid and a diminution in the acidity of the urine resulted in a decrease of the vitamin $C$ content of the urine, and it seems quite possible that this may be a factor of importance in acute rheumatic fever in producing an abnormally high excretion of vitamin $C$. 
TABLE 6

\section{THE EFFECT OF DAILY ADMINISTRATION OF SODIUM SALICYLATE 50 GRAINS AND SODIUM BICARBONATE 100 GRAINS ON THE EXCRETION OF VITAMIN C IN THE URINE OF 15 OF THE CONTROL CHILDREN (TABLE 1).}

Average excretion of ascorbic acid per 24 hours in control period $=12 \cdot 2 \mathrm{mgm}$.

$$
\text { Range }=4 \cdot 5-35 \cdot 7 \mathrm{mgm} \text {. }
$$

Average excretion of ascorbic acid per 24 hours during salicylate therapy $=$ $15.9 \mathrm{mgm}$.

$$
\text { Range }=6.7-50.7 \mathrm{mgm} .
$$

Another factor that was considered to be worth investigating was that of fever. A number of children suffering from active chorea were treated with injections of typhoid vaccine and an artificial fever thus induced. The method of Sutton (1933) was used with increasing daily doses. The temperature reaction reached $103^{\circ}-104^{\circ} \mathrm{F}$. in one to two hours and then gradually subsided to normal. The average daily excretion of ascorbic acid was estimated before and during this treatment and the results are recorded in table 7. The average output before treatment was $13.0 \mathrm{mgm}$. in twenty-four hours. The average daily excretion during fever treatment was $14.7 \mathrm{mgm}$. This is a slight but definite increase and would indicate that the presence of fever will augment the daily excretion of vitamin $C$ in the urine. Nearly all the cases of acute rheumatic fever referred to in table 4 had some elevation of temperature at the time of collection of specimens of urine, but it was not elevated to the degree obtained by typhoid vaccines. On the other hand, the artificially induced fever only lasted for two or three hours out of the twenty-four.

TABLE 7

THE EFFECT OF FEVER INDUCED BY TYPHOID VACCINE ON THE EXCRETION OF VITAMIN C IN THE URINE

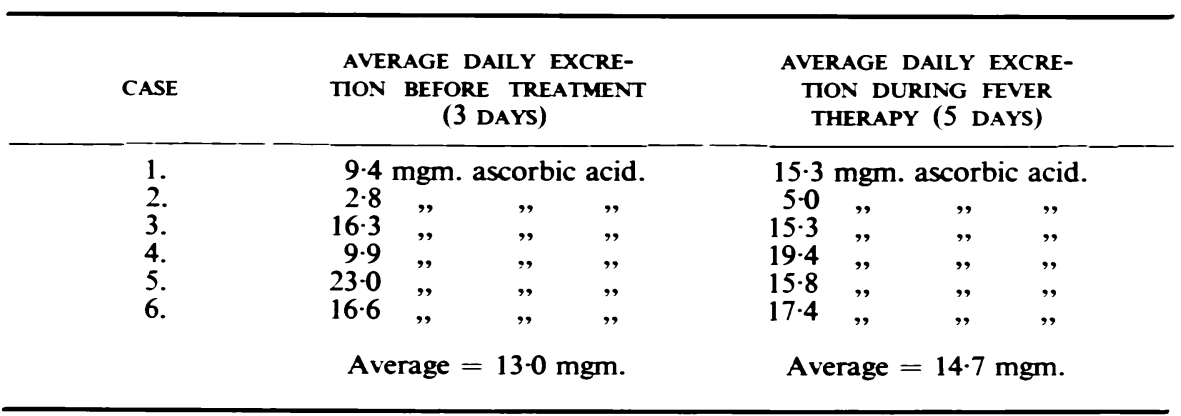




\section{Comment}

The study of infants suffering from scurvy by means of the urinary estimation of vitamin $C$ has shown there is a marked diminution in the daily excretion of ascorbic acid even when quantities are administered by mouth, but for the diagnosis of this disease it is necessary still to depend on the clinical and radiological findings rather than the excretion of the vitamin. This is even more true since the recent studies of Park (1935) and co-workers, who have pointed out in detail the earliest radiological changes of scurvy. The same may be said for the recognition of the various stages in the healing process ; the skiagrams indicate the progress of the patient more acurately than do the biochemical estimations of vitamin $C$ in the urine.

In the course of this investigation a number of interfering factors producing variations in the excretion of vitamin $C$ in the urine have been studied. Some of these have already been referred to in the recent literature. Medication in rheumatic fever was found to increase the excretion of ascorbic acid. Elevation of temperature appears to have a less obvious effect. Infection definitely diminishes the stores of vitamin $C$ in the body and tends to produce minor degrees of deficiency. The acidity or alkalinity of the urine affecting the excretion of ascorbic acid has been investigated by Hawley and Stephens, and they have suggested that there are probably several other unknown factors that interfere with the correct evaluation of these tests. Absorption and utilization are among these.

Parsons (1938) in the Withering Lectures discusses some of the factors producing variations in the excretion of vitamin $C$. He points out that the error due to certain interfering substances in the urine can be eliminated when testing for vitamin $\mathrm{C}$ by doing two separate estimations. An ordinary estimation is done and one after warming with a small amount of copper sulphate to destroy the vitamin, and the difference between the two results indicates the full amount of ascorbic acid excreted. This was not done in this study, but it seems possible to draw certain general conclusions from the comparative results obtained in this investigation. The presence of infection in the body will frequently diminish the stores of vitamin $C$, thus gradually reducing the average daily output and the response to test doses. This has been borne out by all recent investigations. In this series, the rheumatic fever patients did not show this to the same extent as other types of infection. The response to test doses indicates some deficiency, but the daily output was increased. When these patients were investigated two or three months later in the convalescent home, they showed no deficiency either in daily output or response to test doses. The average daily output was almost the same as the age group six to thirteen years in the controls (table 1). The rheumatic patients were in this age group and therefore should be compared with them. The high values recorded in this paper for excretion of vitamin $C$ in the acutely active stage of rheuratic fever may be the result of several factors mentioned previously. They are considerably higher than those reported by Abbasy (1936), but it may be that 
the patients studied here were in a more acute phase of the disease. Again the two series are not exactly comparable, because these results have not been related to body weight as was done by Abbasy and co-workers.

The results of this investigation support those of Sendroy and Schultz (1936), Perry (1935) and others, who found no direct evidence to support the concept that rheumatic fever is a manifestation of a deficiency of vitamin C. The conclusions reached by Abbasy and others (1936) concerning the diagnostic use of this biochemical test for vitamin $C$ in rheumatic fever appear unwarranted by their own results, since they found the same degree of deficiency in their patients suffering from tuberculosis.

A more accurate method of determining various degrees of vitamin $\mathrm{C}$ deficiency may be evolved which will permit a more satisfactory interpretation of results. In spite of the great volume of work on the subject, the relation of subclinical scurvy and mild vitamin $C$ deficiencies to the etiology and course of various diseases remains almost as vague as before the introduction of the present tests. From the results obtained in this investigation and those accumulating in the literature, it is unlikely that more than a few children over two years suffer from a deficiency of vitamin $C$ sufficient to impair their health in any way.

\section{Summary}

An investigation has been carried out on several groups of children with and without infection to estimate the value of a biochemical test for vitamin $\mathrm{C}$ in the urine and study its use as an indication of various degrees of vitamin $\mathrm{C}$ deficiency.

The limits of the value of this test in determining the various stages of healing in a case of scurvy have been discussed.

A group of thirty-nine children between the ages of two and thirteen years in the medical and surgical wards of the hospital who had little or no evidence of infection were found to have an average daily excretion of $9.7 \mathrm{mgm}$. of ascorbic acid in the urine. The older age group (seven to thirteen years) was found to have an average daily excretion of $11.5 \mathrm{mgm}$., while the average of the younger group (two to six years) was $5.5 \mathrm{mgm}$. Marked individual variations were noted.

Children with acutely active rheumatic fever were found to excrete more vitamin $\mathrm{C}$ than convalescent patients. The convalescent rheumatic patients excreted an amount approximately the same as controls in a similar age group.

Saturation tests revealed a slight deficiency in the stores of the vitamin in active rheumatic fever patients as compared with convalescent rheumatics or controls.

The administration of sodium salicylate ( 50 grains) and sodium bicarbonate (100 grains) was found to increase the excretion of vitamin $C$ in the urine.

Artificially induced fever by the use of typhoid vaccine produced a slight increase in the excretion of vitamin $C$.

No direct evidence was found to support the theory that rheumatic fever is a manifestation of a vitamin $\mathrm{C}$ deficiency associated with an infection. 
The authors wish to express to Professor L. G. Parsons their appreciation of his interest and helpful advice in carrying out this investigation. The authors are also indebted to the Medical Research Council for part of the expenses of this investigation and a personal grant to one of them (E. M. H.).

\section{REFERENCES}

Abbasy, M. A., Hill, N. G., and Harris, L. J. (1936). Lancet, 2, 1913.

Archer, H. E., and Graham, T. (1936). Ibid., 1, 710.

Harde, E., and Phillippe, M. C. R. (1934). Acad. Sci., 199, 618, 738.

_ and Rothstein, I. A. (1935). Proc. Soc. exp. Biol. N.Y., 32, 1008.

Harris, L. J., and Ray, S. N. (1935). Lancet, 1, 71.

Hawley, E. E., Stephens, D. J. and Anderson, G. (1936). J. Nutrit., 11, 135.

—, Daggs, R. G., and Stephens, D. J. (1937). Ibid., 14, 1.

Hess, A., and Benjamin, H. R. (1934). Proc. Soc. exp. Biol. N.Y., 31, 855.

Park, E. A., Guild, H. G., Jackson, D., and Bond, M. (1935). Arch. Dis. Childh., 10, 265.

Parsons, L. G. (1938). Lancet, 1, 65, 123.

Payne, W. W. (1936). Arch. Dis. Childh., 11, 257.

Perry, C. B. (1935). Lancet, 2, 426.

Rhinehart, J. F., and Mettier, S. R., (1934). Amer. J. Path., 10, 61.

Rohmer, P., Sanders, N., and Bezssonoff, N. (1934). Nature, 134, 142.

Sendroy, J., and Schultz, M. P. (1936). J. clin. Invest., 15, 369.

Sutton, L. P., and Dodge, K. G. (1933). J. Pediat., 3, 813. 